\title{
VALUING THE SERVICES OF COASTAL ECOSYSTEMS: A META-ANALYSIS OF CONTINGENT VALUATION STUDIES
}

\author{
D. LATINOPOULOS \\ Department of Civil Engineering, Aristotle University of Thessaloniki, Greece.
}

\section{ABSTRACT}

Coastal ecosystems provide many and diverse functions, creating significant environmental values that should be taken into consideration during coastal management decisions. The most widely used method in coastal ecosystem valuation is contingent valuation, a method that can deal with the assessment of direct and indirect ecosystem uses and also of non-use motivations in natural resource economics. In this framework, the main aim of the present paper is to statistically examine the variation of coastal ecosystem values, as derived from 20 contingent valuation case studies. More precisely, this variation is explained by means of a meta-analysis application (meta-regression analysis), where the dependent variable is the willingness to pay for coastal ecosystems protection (or restoration), whereas the set of explanatory variables comprise three main categories of primary studies' characteristics: (a) the environmental characteristics of the reference sites, (b) the site characteristics and (c) the methodological characteristics of the contingent valuation studies. The results of this paper show that all three categories comprise significant factors that explain the heterogeneity in coastal ecosystem values. Moreover, it has been found that specific site characteristics, such as the size of the reference coastal areas and the major environmental threats within these areas, are the most significant determinants of the variation in the willingness to pay. Finally, according to the outcome of a benefit transfer exercise performed on the results of the meta-regression analysis, the accrued set of estimators can be further applied in order to form a generalized benefit transfer function for the assessment of other coastal ecosystems.

Keywords: benefit transfer, coastal ecosystems, contingent valuation, meta-analysis, meta-regression analysis, willingness to pay.

\section{INTRODUCTION}

There are many reasons that justify the valuation of coastal ecosystems. First of all, their valuation can be a useful tool for coastal planning, as it can provide significant information to the decisionmakers on the economic results of the most important environmental impacts arising from various planning decisions. In other words, in several land and resource use choices, as well as investment decisions, the full range of their associated long-term environmental and socio-economic effects can be taken into account. In addition, an accurate and meaningful valuation of coastal ecosystems can provide the environmentalists with the opportunity to measure the costs and benefits of all the necessary conservation measures (actions) and, thus, secure, or at least justify, the financial reasoning for a sustainable coastal management.

Coastal ecosystems can usually supply a variety of products and services, thus leading to numerous different attributes that can be valuated. A significant part of these attributes can be only valuated either as indirect benefits or as non-use values. For this reason, the contingent valuation (CV) approach is quite often used in these systems, as it is the only economic method that can deal with the assessment of non-use motivations in natural resource accounting, as well as the assessment of both direct and indirect environmental values. According to the definition of Mitchell and Carson [1], contingent valuation is a stated preference survey method, which elicits people's willingness to pay (WTP) or willingness to accept (WTA) compensation for a specific change of a non-market good. Specifically, when applied in the field of coastal ecosystems, a CV method aims at: (a) establishing a hypothetical market by providing some basic information on the coastal ecosystem services, (b) specifying the most appropriate payment rules and vehicles; and (c) asking the valuation questions, usually in the form of people's WTP for avoiding an environmental degradation.

(C) 2010 WIT Press, www.witpress.com

ISSN: 1743-7601 (paper format), ISSN: 1743-761X (online), http://journals.witpress.com DOI: $10.2495 /$ SDP-V5-N1-13-30 
The main objective of the work presented in this paper is to examine the variation in economic values of coastal ecosystems, as derived from a selected set of CV case studies. Moreover, this variation is attributed to some specific determinants of the case study sites. To this end, a meta-analysis is performed, aiming to include, compare, evaluate and apprehend the most common elements, as comprised in the selected set of valuation studies. Meta-analysis is a statistical method which aims at integrating a set of research findings coming from various studies that deal with the same subject, usually by means of a regression model (known as meta-regression model).

Some similar studies, in which meta-analysis is employed, focus on the field of wetland valuation [2-6]. Closer to the methodology, as well as to the objectives of this paper, are the studies of: (a) Brouwer et al. [2], where a meta-analysis of CV studies devoted to wetland valuation is undertaken; and (b) Enjolras and Boisson [6], where special emphasis is given to the specification of the resource undervaluation, by particularly examining the lagoon ecosystems (i.e. the part of coastal ecosystems that comprises vast littoral wetland areas with low depth, separated from the sea by a strip of land). The present paper contributes in that the analysis is specific in both the methodological structure (CV studies) and the natural resource determination (coastal ecosystems).

The rest of the paper is organized into four sections. Section 2 concerns the general description and classification of the main economic values of coastal ecosystems. Section 3 describes the theoretical framework of the meta-analysis application, as well as the reference CV studies that are used as meta-data in this application. Section 4 presents the outcome of the meta-analysis procedure, including the meta-regression analysis results and the validation of the regression model. Section 5 presents the conclusions of this paper.

\section{THE VALUES OF COASTAL ECOSYSTEMS}

Prior to the assessment of the environmental values of coastal ecosystems, it is necessary to define the physical boundaries of a coastal ecosystem and then to explore all the potential environmental values comprised within these boundaries. In order to tackle the first task, it can be presumed that the physical characteristic that qualifies an ecosystem as 'coastal' is its proximity to the coast. Therefore, the boundaries of coastal ecosystems are determined by the 'coastal zones', which, according to Carter [7], are 'the areas (spaces) where territorial environments are influenced by maritime ones and vice versa'. The width of a coastal zone is variable and can change over time. Consequently, it is not always possible to limit the coastal zone, especially in those cases when its boundaries are characterized by an environmental gradient or transition. For this reason, the meta-analysis adopted herein differs from the usual approach $[3,4,6]$, according to which all environmental values are converted on a per area basis (e.g. US\$ per acre), and thus the coastal ecosystem values applied during the proposed analysis are left totally unrelated to the size of the study area.

The number and magnitude of environmental values that characterize an ecosystem are interrelated to the ecosystem functions. According to De Groot et al. [8], the ecosystem functions amount to the capacity of natural processes and components to provide goods and services that satisfy human needs, directly or indirectly. Within this framework, there are many and diverse ecosystem functions - and therefore ecosystem values - that can be attributed to coastal ecosystems, as they usually provide a significant number of goods and services. For instance, coastal ecosystems are the main producers of fish, shellfish and seaweed, as well as sources of medicines, cosmetics, fertilizers and construction material products. They are also the habitats of various important species, thus they play a very important role in the provision and maintenance of biodiversity. Considering their services, they can be distinguished into the following categories: (a) filtering pollutants from inland freshwater systems; (b) cycling nutrients; (c) protecting the shorelines from storms, waves and erosion; (d) providing the basic ports for marine commerce; 


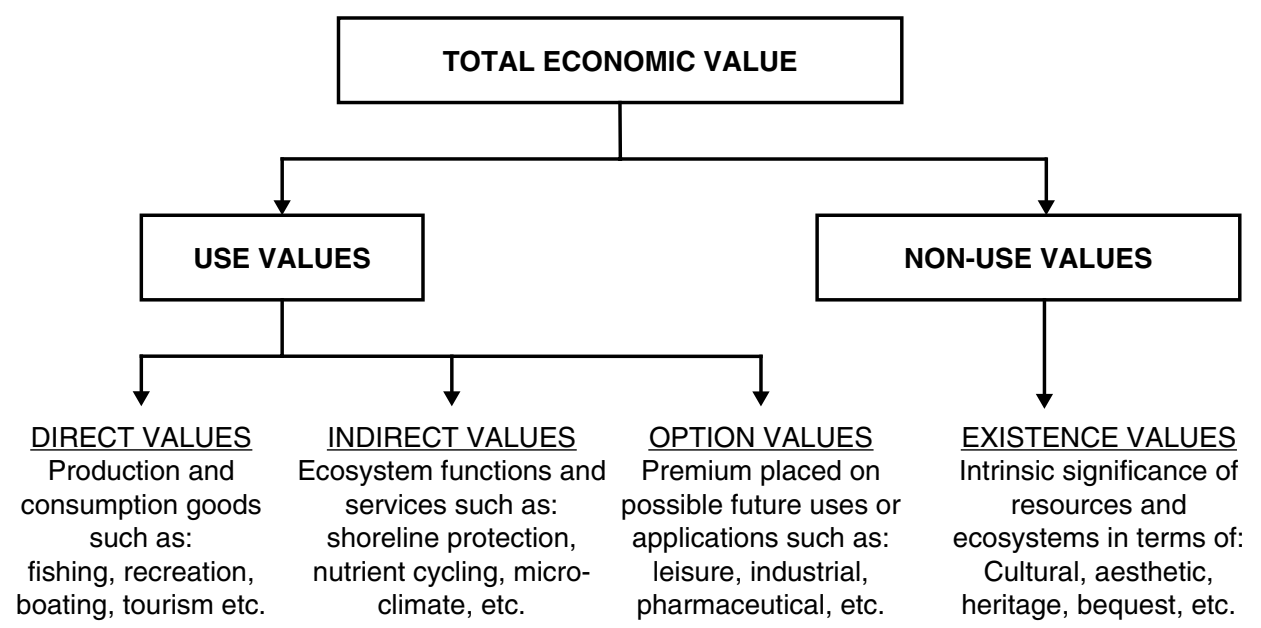

Figure 1: The total economic value of coastal ecosystems (adapted from [10]).

and (e) constituting important sites of tourism and recreational activities. In addition, according to Costanza et al. [9], 37\% of the value of the world's ecosystem services and natural capital is generated by coastal ecosystems.

Following the general concepts of environmental valuation, the total economic value of coastal ecosystems can be considered as the sum of the use and non-use values. Use values can be further distinguished into direct, indirect and option values. The above-mentioned classification is depicted in Fig. 1. As shown in this figure, the main values of coastal ecosystems are the following:

1. Direct values: Raw materials, physical products and services coming directly from catchments or interactions with the environmental coastal systems.

2. Indirect values: Ecological functions that maintain or protect the natural and human environment and provide essential life support. These values are usually linked to an indirect change in the production or consumption values.

3. Option values: Values given from the actual population to the protection of natural resources and environmental services for potential future uses, under the assumption that these uses will have an economic output.

4. Existence values: Intrinsic values of coastal ecosystems, regardless of the possible economic benefits from their current or future use.

\section{APPLICATION OF THE META-ANALYSIS}

\subsection{Theoretical framework}

During the last 20 years, meta-analysis has played a significant role in the field of environmental economics. By definition, meta-analysis is a synthesis of results and findings of several scientific studies - conducted on a particular subject - from which it is possible to summarize, assess, compare, evaluate and apprehend common elements in these studies. Hence, it enables researchers to explain the differences in outcomes found in single studies on the basis of differences in underlying assumptions, standards of design and/or measurement [2]. 
A great advantage of the meta-analysis technique is that it provides a rigorous statistical synthesis of the literature which cannot be achieved using more qualitative analysis [3]. Subsequently, it can be used as an extension of the traditional methodology of qualitative analysis across similar case studies, supplementing the role of the latter to the assessment of large amounts of secondary data [11].

The general framework of an economic meta-analysis that focuses on environmental valuation consists of the following steps: (a) selecting the most appropriate primary studies (meta-analysis observations), yielding a set of environmental values which will then constitute the dependent variable; (b) coding all the relevant and necessary information out of the characteristics of both the study area and the applied methodology (meta-analysis explanatory variables); and (c) analyzing the coded data with reference to the environmental values. It should be mentioned that it is common practice to use more than one observation from a study, if it presents multiple values that can be attributed to variations of the relevant characteristics [12].

The context of this paper requires the analysis of primary studies (i.e. CV studies of coastal ecosystem valuation) that can provide a substantial set of characteristics, at the same time minimizing the missing data of those characteristics across studies (the limited number of primary studies underlines the need to minimize missing data). As already mentioned, the main objective herein is to examine the variation of coastal ecosystem values. This variation should be explained by means of significant differences in three main categories of studies' characteristics: (a) the environmental characteristics of each study area, (b) the main values under examination (according to the classification presented in Fig. 1) and (c) the most important methodological characteristics of the various CV surveys. Therefore, the general mathematical form of the current meta-analysis is expressed by the following equation:

$$
\mathrm{CE} \_\mathrm{WTP}=f\left(\mathrm{SC}_{i}+\mathrm{VC}_{j}+\mathrm{MC}_{k}\right) \text {, }
$$

where CE_WTP is the annual willingness to pay for coastal protection and/or restoration (per household), $\mathrm{SC}_{i}$ are the study area characteristics, $\mathrm{VC}_{j}$ are the main value categories as indicated in the reference study (all expressed as dummy variables) and $\mathrm{MC}_{k}$ are the most important methodological characteristics.

A particular form of econometric analysis, called meta-regression analysis, is used in order to investigate systematically the above-mentioned relationships. This approach is designed to pool data from the primary studies and then subject the data to multiple regression analysis. The dependent variable of this regression (CE_WTP) is a summary statistic or 'effect size' drawn from each study, while the independent variables - also called 'moderator variables' - include several primary studies' characteristics $\left(\mathrm{SC}_{i}, \mathrm{VC}_{j}, \mathrm{MC}_{k}\right)$ that are assumed to be consequential. The application of the meta-regression analysis aims at determining and quantifying the wide study-to-study variation (heterogeneity) in effect-sizes, by uncovering those variables (characteristics) that seem to explain, as far as possible, the perceived heterogeneity.

\subsection{Description of data}

The results of $20 \mathrm{CV}$ studies, applied in several countries under various ecological and socio-economic conditions, were used in the present meta-analysis. The list of the selected studies is presented in Table 1. As shown in this table, the primary studies employed were published during the last 17 years (seven of them in the 1990s and 13 in the 2000s) and are mainly focused on coastal water quality. A reason for this specific selection is that a meta-analysis with such a confined scope can provide results with small transfer errors when used for benefit transfer. It is also worth noting that, contrary 
Table 1: Analytic presentation of the studies employed in the meta-analysis.

\begin{tabular}{rllcc}
\hline & Authors & Type of publication & Study year & $n^{\mathrm{a}}$ \\
\hline 1 & Alberini et al. [13] & Journal article (JEAPM) & 2002 & 1 \\
2 & Atkins and Burdon [14] & Journal article (MPB) & 2003 & 1 \\
3 & Barton [15] & Journal article (EE) & 1998 & 2 \\
4 & Brouwer and Bronda [16] & Book chapter & 2002 & 1 \\
5 & Choe et al. [17] & Journal article (LE) & 1994 & 1 \\
6 & Georgiou et al. [18] & Journal article (EPA) & 1995 & 2 \\
7 & Georgiou et al. [19] & Journal article (RDP) & 2000 & 1 \\
8 & Goffe [20] & Journal article (JEM) & 1993 & 2 \\
9 & Goodman et al. [21] & Journal article (JEPM) & 1995 & 1 \\
10 & Hanley and Kristrom [22] & Scientific report & 2000 & 1 \\
11 & Jones et al. [23] & Journal article (JSE) & 2006 & 1 \\
12 & Kontogianni et al. [24] & Journal article (EE) & 1998 & 3 \\
13 & Kontogianni et al. [25] & Journal article (WRM) & 1999 & 1 \\
14 & Lindahl and Söderqvist [26] & PhD thesis & 1999 & 1 \\
15 & Lipton [27] & Journal article (MRE) & 2000 & 1 \\
16 & Machado and Mourato [28] & Working paper & 1997 & 1 \\
17 & Mourato et al. [29] & Working paper & 2002 & 1 \\
18 & Niklitschek and Leon [30] & Journal article (JEEM) & 1992 & 1 \\
19 & Saengsupavanich et al. [31] & Journal article (EE) & 2006 & 1 \\
20 & Zylick et al. [32] & Working paper & 1994 & 1 \\
\hline
\end{tabular}

EE: Ecological Economics; EPA: Environment and Planning A; JEAPM: Journal of Environmental Policy and Management; JEEM: Journal of Environmental Economics and Management; JEM: Journal of Environmental Management; JEPM: Journal of Environmental Planning and Management; JSE: Journal of Socio-Economics; LE: Land Economics; MPB: Marine Pollution Bulletin; MRE: Marine Resource Economics; RDP: Risk Decision and Policy; WRM: Water Resources Management. ${ }^{a}$ Number of observations taken from each study.

to the existing experience in the meta-analysis research, the present application comprises only a few studies in the dataset which have more than one observation $(20 \%$ of observations come from the same surveys and/or the same sample population). This is not necessarily a drawback, since multiple results from the same study cannot always be treated as independent observations, especially in those cases when they present some intra-study correlation (e.g. being derived from the same data, estimated using the same methods, influenced by the researcher's expectations). On the other hand, because of the limited number of CV studies valuating the coastal ecosystems, it was not feasible to eliminate the risk of having an 'authorship effect', which can arise when using primary studies produced by the same researchers.

From the large variety of all functions of coastal ecosystems appearing in the primary studies, quite a few were actually valuated. The most important functions, and consequently coastal ecosystem values, of the selected dataset are the following: (a) recreational activities, such as bathing, fishing, boating, water-sports and camping; (b) biodiversity protection, increase of wildlife and ecosystem preservation; (c) public health benefits (this function is partly related to the bathing activities); (d) reduction of unpleasant odours; and (e) environmental benefit assessments solely based on a better water environment per se (bequest or existence values). 
Apparently, all the above-mentioned functions could not be incorporated in the meta-analysis procedure because of the limited number of observations. Hence, a general classification, based on Fig. 1, was adopted, according to which special emphasis is put on the following three categories of environmental values: (a) direct values (functions) of coastal ecosystems, (b) indirect values and (c) bequest and/or existence values. Thus, the sample of observations was classified into each of these categories according to the main value assessed in each case study. However, it should be noted that it was not possible to assign a cardinal value category to all studies, as about one-third of them attempt to simultaneously valuate multiple benefits of coastal ecosystems (these multiple effects were equivalently incorporated into the regression matrix).

The dependent variable in the meta-regression analysis is the per-household annual average WTP for the protection of the coastal environment. In order to have comparable values for all the case studies, the individual WTP estimates were first expressed in national currencies in terms of their 2005 purchasing power of money (by means of GDP deflators). Then, these values were all converted into 2005 US dollars, according to the national currency rates of January 2005.

All the explanatory variables initially included in the meta-analysis procedure are presented in Table 2 . The first category of explanatory variables consists of the study area characteristics $\left(\mathrm{SC}_{i}\right)$. The study area characteristics employed herein are the following: the country profile, the environmental pressures and the size of the area under valuation. Regarding the country of the survey research, it was not possible to differentiate between developed and developing countries because the vast majority of reference sites belong to the developed ones. So, the sample was divided into European and non-European countries. Moreover, the environmental pressures were expressed through the three most commonly mentioned environmental problems in the reference sites: the bacteriological, the eutrophication and the erosion threats. These were inserted in the model as three independent dummy variables. Finally, the size of the area, which is usually treated as a continuous variable in similar studies, due to the specific spatial characteristics of coastal areas, is converted into a dummy variable indicating whether the survey site is limited to a specific coastal area or it covers a whole regional (or even national) coastline.

The variables referring to the main values under examination $\left(\mathrm{VC}_{j}\right)$ are three dummy ones, indicating the already mentioned relative categories (direct, indirect and existence values). In addition, a set of seven explanatory variables related to the methodology characteristics - a typical category in the meta-analysis theory - is used in order to further explain the heterogeneity of the coastal ecosystem values. Future environmental scenarios, specific actions for coastal preservation, the visual depiction of environmental problems, the target group of the valuation study, the method of interview and the WTP question (elicitation) format are all dummy variables of the survey characteristics, while the higher bid amount (in studies with a referendum format) is the only continuous variable.

It should be noted that the response rate of the interviews was not included in the present meta-analysis despite the fact that it is a reliable indicator of the validity and the representativeness of each study. The rationale for this exclusion is that it was very difficult to distinguish the characteristics of non-response in the sample of primary studies. Specifically, only half of them report separately the percentages of protest votes and response rates, while very few mention analytically the criteria for excluding non-responders.

\subsection{Summary statistics}

\section{RESULTS AND DISCUSSION}

An initial understanding of the level of variation of coastal ecosystem values, as well as of the explanatory power of the selected variables in this variation, can be attained by means of a summary statistics analysis. In Table 3 the summary statistics of the dependent variable are shown as both 
Table 2: Description of the initial set of variables included in the meta-analysis.

\begin{tabular}{|c|c|c|}
\hline Category & Variable & Variable description \\
\hline Dependent variable & CE_WTP & $\begin{array}{l}\text { Annual willingness to pay for costal ecosystem protection } \\
\text { and/or restoration, in US\$ per household, standardized to } \\
\text { base year } 2005\end{array}$ \\
\hline \multirow{6}{*}{$\begin{array}{l}\text { Study area } \\
\text { characteristics } \\
\left(\mathrm{SC}_{i}\right)\end{array}$} & COUNTRY & $\begin{array}{l}0=\text { Other countries } \\
1=\text { European countries }\end{array}$ \\
\hline & BACTER & $\begin{array}{l}\text { Bacteriological contamination is the main problem: } \\
0=\text { No } \quad 1=\text { Yes }\end{array}$ \\
\hline & EUTRO & Eutrophication is the main problem: \\
\hline & & $0=$ No $\quad 1=$ Yes \\
\hline & EROSION & $\begin{array}{l}\text { Coastal erosion is the main problem: } \\
0=\text { No } \quad 1=\text { Yes }\end{array}$ \\
\hline & AREA & $\begin{array}{l}0=\text { Small coastal area is valuated } \\
1=\text { A wider coastal area is valuated }\end{array}$ \\
\hline \multirow[t]{4}{*}{$\begin{array}{l}\text { Main value under } \\
\text { examination } \\
\left(\mathrm{VC}_{j}\right)\end{array}$} & DIRECT & $\begin{array}{l}\text { Direct use values are mainly valuated } \\
\text { (Recreational values such as swimming, fishing, boating, etc.): } \\
0=\text { No } \quad 1=\text { Yes }\end{array}$ \\
\hline & INDIRECT & $\begin{array}{l}\text { Indirect use values (beneficial services through ecological } \\
\text { processes and functions) are mainly valuated: }\end{array}$ \\
\hline & & $0=$ No $\quad 1=$ Yes \\
\hline & EXIST & $\begin{array}{l}\text { Existence and bequest values are mainly valuated: } \\
0=\text { No } \quad 1=\text { Yes }\end{array}$ \\
\hline \multirow[t]{7}{*}{$\begin{array}{l}\text { Methodology } \\
\text { characteristics }\left(\mathrm{MC}_{k}\right)\end{array}$} & SCENARIO & $\begin{array}{l}0=\text { The future environmental scenarios are not clearly } \\
\text { presented } \\
1=\text { The interviewer presents analytically the future } \\
\text { environmental scenarios }\end{array}$ \\
\hline & ACTION & $\begin{array}{l}0=\text { No action is presented in order to confront current or } \\
\text { potential environmental threats } \\
1=\text { The interviewer introduces a specific coastal protection } \\
\text { (or restoration) action plan that is going to be implemented }\end{array}$ \\
\hline & VISUAL & $\begin{array}{l}\text { Visual depiction of the most important (under valuation) } \\
\text { environmental problems of the coastal ecosystem: } \\
0=\text { No } \quad 1=\text { Yes }\end{array}$ \\
\hline & TARGET & $\begin{array}{l}0=\text { Target group of the valuation study are only local } \\
\text { residents }\end{array}$ \\
\hline & INTERVIEW & $\begin{array}{l}1=\text { Tourists and/or beach users are also interviewed } \\
\text { CVM interview method: } \\
0=\text { Telephone or mail interviews } \\
1=\text { In person interviews }\end{array}$ \\
\hline & PQUEST & $\begin{array}{l}\text { WTP question: } \\
0=\text { Dichotomous choice, iterative bidding or payment } \\
\text { cards }\end{array}$ \\
\hline & HIGHBID & $\begin{array}{l}1 \text { = Open ended valuation question } \\
\text { Higher bid (applied only in studies with referendum } \\
\text { valuation format) }\end{array}$ \\
\hline
\end{tabular}


Table 3: Summary statistics of the dependent variable - test of normality.

\begin{tabular}{|c|c|c|c|c|c|c|}
\hline & & & \multicolumn{2}{|c|}{ WTP } & \multicolumn{2}{|c|}{$\log$ WTP } \\
\hline Number of & servations & & \multicolumn{2}{|c|}{25} & \multicolumn{2}{|c|}{25} \\
\hline Mean & & & \multicolumn{2}{|c|}{64.31} & \multicolumn{2}{|c|}{1.66} \\
\hline Standard e & $r$ of mean & & \multicolumn{2}{|c|}{9.74} & \multicolumn{2}{|c|}{0.08} \\
\hline Median & & & \multicolumn{2}{|c|}{52.30} & \multicolumn{2}{|c|}{1.72} \\
\hline Standard d & ation & & \multicolumn{2}{|c|}{48.70} & \multicolumn{2}{|c|}{0.40} \\
\hline Range & & & \multicolumn{2}{|c|}{163.80} & \multicolumn{2}{|c|}{1.60} \\
\hline Minimum & & & \multicolumn{2}{|c|}{4.20} & \multicolumn{2}{|c|}{0.62} \\
\hline \multirow[t]{3}{*}{ Maximum } & & & \multicolumn{2}{|c|}{168.00} & \multicolumn{2}{|c|}{2.23} \\
\hline & \multicolumn{3}{|c|}{ Kolmogorov-Smirnov } & \multicolumn{3}{|c|}{ Shapiro-Wilk } \\
\hline & Statistic & df & Sig. & Statistic & $\mathrm{df}$ & Sig. \\
\hline WTP & 0.174 & 25 & 0.049 & 0.892 & 25 & 0.012 \\
\hline $\log$ WTP & 0.091 & 25 & 0.200 & 0.955 & 25 & 0.317 \\
\hline
\end{tabular}

actual and logarithmic values. The mean WTP for coastal ecosystem preservation is $64.3 \$ /$ household/ year when the actual values are used and $45.7 \$$ /household/year when the logarithmic transformation is considered. The minimum and maximum values of the WTP in the primary studies were equal to $4.2 \$ /$ household/year and $168 \$ /$ household/year, respectively. In order to test the normality of the coastal ecosystem values, the Kolmogorov-Smirnov test of normality was applied. The results of this test, also presented in Table 3, denote that the hypothesis of normal distribution cannot be rejected only in the logarithmic transformation of the WTP values. For this reason, in the following meta-regression analysis the log values of WTP will be used. This distribution, along with the relative frequencies of the log WTP values are displayed in Fig. 2.

For the examination of the explanatory power of the selected variables, the WTP values (log values) are partitioned into several potential explanatory factors (as initially selected in the previous section). The summary statistics of the explanatory variables are presented in Table 4. As shown in the last column of this table, the calculated differences in the mean WTP values were found to be statistically significant at the $10 \%$ significance level ( $t$-test statistics and one-way ANOVA application) in 4 out of the 10 selected factors (namely, the environmental threat, the relative coastal area size, the value type and the future scenarios).

Analytically, the effect of the selected factors on the value of coastal ecosystems is as follows:

- The mean WTP for coastal ecosystem protection seems to be significantly lower in the European countries than the rest of the world.

- Looking at the environmental threats, the bacteriological threats generate the highest mean WTP, followed by the erosion and the eutrophication threats.

- The size of coastal areas under valuation is negatively related to the coastal ecosystem values. Namely, the mean WTP for small coastal areas is more than double that of the larger ones.

- Among all coastal ecosystem functions, the direct use functions have a great influence on the mean WTP. This is a common outcome in meta-analyses dealing with environmental valuation. Furthermore, it can be inferred that the mean WTP estimates of the existence values approximate 


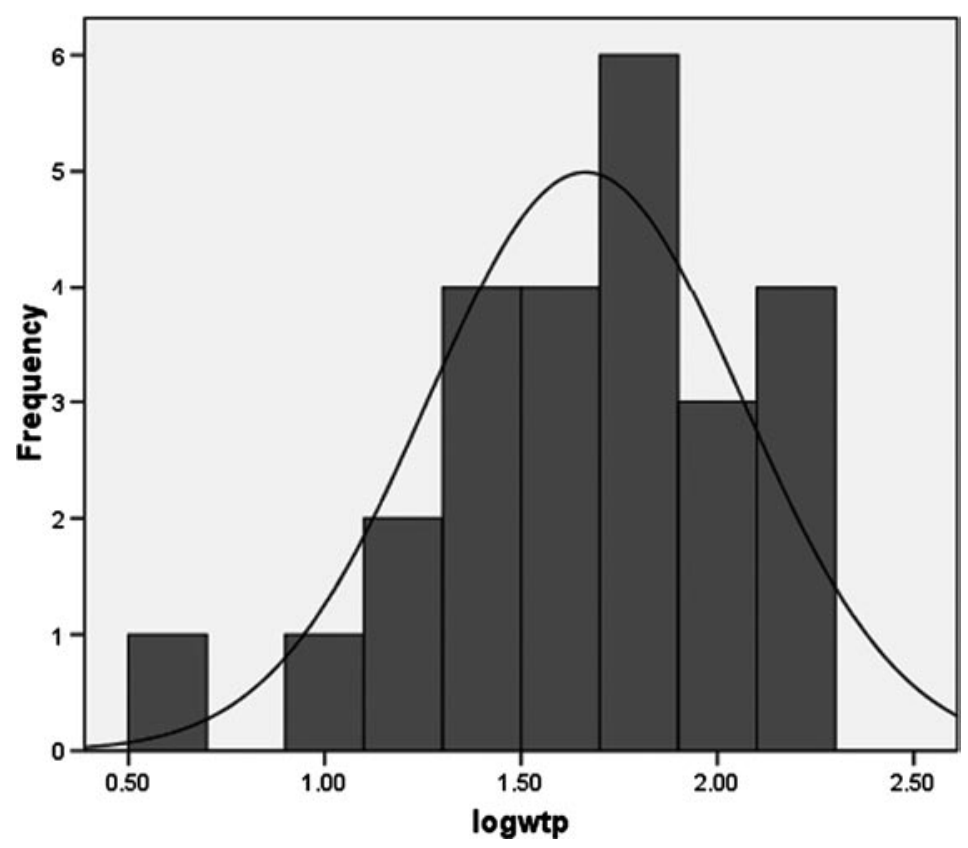

Figure 2: Sample distribution of the log values of WTP.

the sample mean WTP, while the indirect functions of coastal ecosystems provide quite lower values than the former two categories. A possible explanation for this result is that indirect values may not be always well perceived by the $\mathrm{CV}$ respondents.

- The analytical and clear presentation of the proposed (future) environmental scenarios (under various policy measures) has, as expected, a significant positive effect on the values of coastal ecosystems. On the other hand, there are no significant differences in the mean values of WTP for the following factors: (a) analytical action proposed (for environmental protection or restoration), (b) visual depiction of environmental problems and (c) target group of the valuation study.

- As regards the interview method, personal interviews yield higher average values of WTP than the telephone and mail ones.

- Finally, in contrast to some previous research results ([2, 33]), open-ended questions result in higher WTP than other kinds of elicitation formats (e.g. dichotomous choice, iterative bidding or payment cards). One possible reason for this is that some of the primary studies using the referendum format constrain the respondents to select quite low bidding values (significantly lower than the sample mean value). For this reason, the effect of bidding values will be further examined in the next section, during the meta-regression analysis.

\subsection{Meta-regression analysis results}

The next task of this paper is to form the meta-regression econometric model. The ordinary least square technique was used to estimate the meta-regression function. The variables already presented in Table 2 were used as initial regression variables. However, in order to select the most representative variables, it was essential to eliminate the correlated ones and then perform a backward stepwise regression (where the criterion of $p=0.10$ or less was used). A log-linear model was implemented, 
Table 4: Summary statistics of the main explanatory variables.

\begin{tabular}{|c|c|c|c|c|}
\hline Variable & $\begin{array}{l}\text { Mean WTP } \\
\text { (2005 US\$) }\end{array}$ & $\begin{array}{l}\text { Standard } \\
\text { error }\end{array}$ & $n^{\mathrm{a}}$ & $\begin{array}{c}t \text {-Value/ } F \text {-value } \\
\text { (sig.) }\end{array}$ \\
\hline Country & & & & $1.4(0.187)$ \\
\hline European countries & 40.12 & 0.153 & 19 & \\
\hline Other countries & 71.36 & 0.091 & 6 & \\
\hline Environmental threat & & & & $4.3(0.050)$ \\
\hline Bacteriological threat & 51.24 & 0.116 & 11 & \\
\hline Eutrophication threat & 31.65 & 0.182 & 6 & \\
\hline Erosion threat & 46.07 & 0.086 & 3 & \\
\hline Relative coastal area size & & & & $2.4(0.024)$ \\
\hline Local area valuated & 59.37 & 0.075 & 18 & \\
\hline Wider area valuated & 23.99 & 0.177 & 7 & \\
\hline Value type & & & & $2.8(0.081)$ \\
\hline Direct use values & 86.71 & 0.128 & 8 & \\
\hline Indirect use values & 31.70 & 0.116 & 7 & \\
\hline Existence values & 50.82 & 0.137 & 6 & \\
\hline Future scenarios & & & & $-1.8(0.097)$ \\
\hline Analytical future scenarios & 59.24 & 0.122 & 14 & \\
\hline Ambiguous scenarios & 33.44 & 0.081 & 11 & \\
\hline Action proposed & & & & $-0.5(0.616)$ \\
\hline Analytical action proposed & 50.82 & 0.102 & 12 & \\
\hline No action proposed & 42.07 & 0.124 & 13 & \\
\hline Visual & & & & $-0.8(0.453)$ \\
\hline Visual depiction & 53.33 & 0.140 & 12 & \\
\hline No visual depiction & 40.18 & 0.085 & 13 & \\
\hline Target & & & & $-0.8(0.429)$ \\
\hline Local residents & 58.48 & 0.137 & 7 & \\
\hline Tourist and beach users & 41.88 & 0.098 & 15 & \\
\hline Interview method & & & & $-1.1(0.298)$ \\
\hline Personal interviews & 51.40 & 0.089 & 20 & \\
\hline Telephone or mail interviews & 31.19 & 0.174 & 5 & \\
\hline Elicitation format & & & & $1.4(0.180)$ \\
\hline Open-ended valuation & 56.49 & 0.076 & 14 & \\
\hline Other elicitation formats & 33.96 & 0.161 & 11 & \\
\hline
\end{tabular}

${ }^{a}$ Number of observations.

bBased on Kolmogorov-Smirnov test results (modified by Lilliefors), the log WTP variable has been examined for normal distribution. In this case, $t$-test statistics and one-way ANOVA were applied (according to the subdivisions of the number of factors), under the null hypothesis of equal average WTP for all groups. The numbers in parenthesis depict the level of significance. 
according to which the log values of coastal ecosystems were used as the dependent variable. The regression function of this model has the following form:

$$
\log \left(\mathrm{CE}_{-} \mathrm{WTP}_{S}\right)=a+\sum_{i} b_{i} \mathrm{SC}_{i S}+\sum_{j} b_{j} \mathrm{VC}_{j S}+\sum_{k} b_{k} \mathrm{MC}_{k S}+u_{S}
$$

where $S$ is the observation (case study) reference number, $a$ is the constant term, $b$ s are the estimated coefficients of the respective explanatory variables and $u_{S}$ is the error term.

It should be noted that a number of variables, which initially entered the model, were later eliminated from the rest of the analysis due to their limited effect in explaining the variation in coastal ecosystem values (the factors that seem to have no significant effect on the average WTP values have already been detected during the summary statistics of the explanatory factors). That is, the variables for COUNTRY, ACTION, VISUAL and TARGET were removed from the final model due to the results of successive backward stepwise regression analyses. The elimination of VISUAL was also due to its high correlation with SCENARIO, while TARGET was significantly correlated with AREA (indicating that most of the small coastal areas are valued in local surveys).

Eventually, 11 explanatory variables were included in three distinct regression models, according to the separation criteria selected by Woodward and Wui [3]:

- Model A: The variation in coastal ecosystem values is assumed to be only due to the study area $\left(\mathrm{SC}_{i S}\right)$ and the main ecosystem values characteristics $\left(\mathrm{VC}_{j s}\right)$.

- Model B: The variation in coastal ecosystem values is assumed to be only due to the individual CV surveys characteristics $\left(\mathrm{MC}_{k S}\right)$.

- Model C: The variation in coastal ecosystem values is based on all three categories of the primary studies' characteristics.

All the variables of the regression model, apart from one (HIGHBID), are dummy variables so that the accrued meta-regression function could be easily applied to any potential policy site. It should also be mentioned that the model fit was considerably improved, and the heteroskedasticity was mitigated, when using the common logarithms of both the dependent and the higher bid (HIGHBID) variables instead of their actual values. The final results of all three models are presented in Table 5.

As concluded by the histograms of residuals and the normal probability plots, the residuals of the above three models do not exhibit any marked pattern or trend. This means that all models provide a good fit and do not violate the assumptions of normality. It should also be mentioned that no outliers were found in the three log-linear models. According to the Durbin-Watson test, there is no significant sign of autocorrelation, while the hypothesis of heteroskedasticity was rejected at the 5\% significance level, based on the results of the Breusch-Pagan test.

The determination $\left(R^{2}\right)$ coefficients of each model (indicators of models' goodness of fit) are presented in the last row of Table 5. According to their values, it seems that the third model $\left(R^{2}=0.605\right)$ has a higher explanatory power, with more than half of the coastal ecosystem valuation heterogeneity being explained by the variation in the selected set of explanatory variables. Regarding the other two models, model A accounts for 38\% and model B for $26 \%$ of the observed heterogeneity in coastal ecosystem values. Based on this outcome, further analysis will specifically focus on the results of model C.

A fact that should be underlined is that in the selected regression model, all linear coefficients measure the proportional or relative (small) changes in the value of coastal ecosystems for a given (small) change in the value of the explanatory variables (after a necessary transformation of the common logarithm to the natural one). For example, a coefficient equal to 0.032 , which corresponds to the binary variable that indicates the existence of bacteriological pollution, means that, ceteris 
Table 5: Meta-regression analysis (ordinary least square) results for the three models.

\begin{tabular}{|c|c|c|c|}
\hline Variable $^{\mathrm{a}}$ & A & B & $\mathrm{C}$ \\
\hline (Constant) & $\begin{array}{l}1.571 * * * \\
(0.180)\end{array}$ & $\begin{array}{l}0.804 * * * \\
(0.219)\end{array}$ & $\begin{array}{l}1.202 * * * \\
(0.338)\end{array}$ \\
\hline BACTER & $\begin{array}{l}0.139 * * \\
(0.059)\end{array}$ & & $\begin{array}{l}0.032 * * \\
(0.015)\end{array}$ \\
\hline EUTRO & $\begin{array}{c}-0.101 * \\
(0.054)\end{array}$ & & $\begin{array}{l}-0.173 * * * \\
(0.053)\end{array}$ \\
\hline EROSION & $\begin{array}{c}0.061 \\
(0.090)\end{array}$ & & $\begin{array}{c}0.330 \\
(0.210)\end{array}$ \\
\hline AREA & $\begin{array}{l}-0.393 * * * \\
(0.151)\end{array}$ & & $\begin{array}{l}-0.254 * * \\
(0.104)\end{array}$ \\
\hline INDIRECT & $\begin{array}{c}-0.292 * \\
(0.163)\end{array}$ & & $\begin{array}{l}-0.057 \\
(0.059)\end{array}$ \\
\hline DIRECT & $\begin{array}{c}0.284^{*} \\
(0.147)\end{array}$ & & $\begin{array}{c}0.445^{*} \\
(0.227)\end{array}$ \\
\hline EXIST & $\begin{array}{c}-0.085 \\
(0.063)\end{array}$ & & $\begin{array}{l}-0.405 \\
(0.311)\end{array}$ \\
\hline SCENARIO & & $\begin{array}{l}0.148 * * * \\
(0.044)\end{array}$ & $\begin{array}{l}0.331 * * \\
(0.146)\end{array}$ \\
\hline PQUEST & & $\begin{array}{l}0.210 \\
(0.500)\end{array}$ & $\begin{array}{l}0.328 * \\
(0.173)\end{array}$ \\
\hline HIGHBID & & $\begin{array}{l}0.379 * * * \\
(0.103)\end{array}$ & $\begin{array}{c}0.108 * \\
(0.060)\end{array}$ \\
\hline INTERVIEW & & $\begin{array}{c}0.189 * \\
(0.105)\end{array}$ & $\begin{array}{c}-0.062 \\
(0.044)\end{array}$ \\
\hline$N$ & 25 & 25 & 25 \\
\hline$R^{2}$ & 0.382 & 0.260 & 0.605 \\
\hline
\end{tabular}

aDependent variable $=$ annual WTP.

Statistically significant at the $* 0.10, * * 0.05$ and $* * * 0.01$ level.

paribus, the value of coastal ecosystems will be $7.4 \%$ higher than the average if they face a bacteriological threat. On the other hand, concerning the logarithmic variable (HIGHBID), its coefficient should be interpreted as an elasticity of the coastal ecosystem values (i.e. 1\% change in coastal ecosystem values given a $10 \%$ change in the higher bid value).

Looking at the last column of Table 5 (i.e. the coefficient estimators of model C), the following inferences can be drawn:

- There is a quite satisfying number of variables (seven) - keeping in mind the relatively small sample size - that were found to be statistically significant at the $10 \%$ level of significance.

- The meta-regression model presents a high and significant constant term, indicating the existence of additional parameters - not included in this model - which can further explain the variation in coastal ecosystem values.

- The most significant explanatory variables are those referring to the study area characteristics $\left(\mathrm{SC}_{i S}\right)$, followed by the methodological $\left(\mathrm{MC}_{k S}\right)$ and the valuation $\left(\mathrm{VC}_{j S}\right)$ characteristics. This is 
actually a desirable outcome in the meta-analysis exercise, because the study area characteristics are the most important determinants of valuation heterogeneity, which should be captured in order to estimate a robust and credible benefit transfer function.

- As already indicated in the summary statistics, bacteriological threats have a positive effect on people's WTP, while eutrophication threats lead to lower coastal ecosystem values. The latter is in contrast to the results of Costanza et al. [9], according to which nutrient cycling is the most important value of coastal ecosystems. The dummy variable of erosion was found to be statistically insignificant, maybe due to the small number of relevant observations.

- Once again, there are no positive 'returns of scale' due to the size of coastal ecosystems. On the contrary, larger sites are related to lower WTP values. This is contrary to the expectations and the findings of previous studies, but it could be partially explained due to the fact that in the selected sample of studies most of the small coastal ecosystems were valuated by means of local surveys. Therefore, the directly affected households may give a higher WTP than what is usually observed in respondents from regional or national surveys.

- There is no remarkable effect caused by the diversification of ecosystem values. Namely, in contrast to Costanza et al. [9], it is only the direct values that have a sizable (positive) impact on coastal ecosystem valuation (possibly due to them being unrelated to the size of the study area values).

- Finally, with regard to the methodology characteristics, the open-ended questions result in higher WTP values than the other elicitation formats (dichotomous choice, iterative bidding and payment cards). On the other hand, CV surveys using the referendum format could also result in high values, under the precondition of avoiding the underestimation of bid prices.

\subsection{Benefit transfer analysis}

The results accrued from the meta-regression analysis can point out the variables that may be important in the future design of similar valuation studies. Furthermore, they can provide quite useful information for any future inquiry, offering the possibility to predict the total environmental value of other - not already valuated - coastal ecosystems (out of sample prediction) by means of a benefit transfer application $[12,34]$.

The benefit transfer method (also called 'value transfer' since the values being transferred can be costs as well as benefits) is defined as the transposition of monetary environmental values estimated at the study sites - through market-based or non-market-based economic valuation techniques - to a policy site [2]. This transposition can be fulfilled by means of a function (benefit transfer function) resulting from the meta-regression analysis. The advantage of this empirical method is that it is far less expensive than the economic valuation of environmental goods but also much easier to be applied. In addition, in those cases where the 'transfer errors' are substantial (e.g. mischaracterization of ecosystem services, no capture of important environmental characteristics, benefit transfer to countries not resembling the selected sample), the benefit transfer function can at least provide an approximate idea of the environmental benefits in the policy sites.

The practice of benefit transfer, and in particular its validity tests, reveals transfer error rates that frequently oscillate between $15 \%$ and $75 \%$ for published studies [35]. For this reason, in order to check the performance of the above model, a classic indicator called 'mean absolute percentage error' (MAPE), can be used [4]. This indicator measures the transfer error rate and its mathematical expression is the following:

$$
\text { MAPE }=\left|\frac{Y_{\text {observed }}-Y_{\text {estimated }}}{Y_{\text {observed }}}\right| .
$$


The application of the MAPE indicator to the sample of the primary studies is useful in order to provide an in-sample forecast performance of our models. The results of applying this procedure to all three models are presented in Table 6 , where it becomes apparent that model $\mathrm{C}$ is by far the most appropriate for the benefit transfer implementation. Namely, its mean average percentage error is equal to $40.1 \%$, while the median transfer error is only $26.7 \%$. In addition, it is worth-mentioning that almost $70 \%$ of the in-sample value transfers report errors lower than $50 \%$.

Furthermore, a jack-knife resampling technique was also used to examine the robustness of using the meta-regression function for an out-of-sample benefit transfer. The conceptual framework of this technique is to successively omit one variable (case study) and then regress separately the $n-1$ models for the observations $(n-1)$ left in the model. The variables of the omitted observations are then applied to the regression parameters and the predicted variables are depicted in a common scattergram with the observed variables. The results of this procedure are presented in Fig. 3. In this figure, the case studies are classified in ascending order (according to the value/household/year) and then both the original and the predicted logarithms of the coastal ecosystem values are represented. It should be noted that the general picture of the out-of-sample validation corresponds with the results associated with similar meta-analysis studies $[4,6]$. Namely, an overvaluation for low coastal ecosystem values and an undervaluation for large coastal ecosystem values can be observed.

Figure 4 represents the transfer error from the jack-knife approach, also ranked in ascending order. The overall transfer error is equal to $48 \%$, i.e. a slightly higher error than the one estimated for the in-sample forecast. In addition, the median transfer error is found to be equal to $35 \%$, whilst

Table 6: In-sample validation results of all regression models.

\begin{tabular}{lccc}
\hline & Model A & Model B & Model C \\
\hline Mean APE (MAPE) & $53.1 \%$ & $85.5 \%$ & $40.1 \%$ \\
Median APE & $59.7 \%$ & $90.4 \%$ & $26.7 \%$ \\
Less than 10\% error (percentage of case studies) & $12.0 \%$ & $4.0 \%$ & $12.0 \%$ \\
Less than 50\% error (percentage of case studies) & $40.0 \%$ & $8.0 \%$ & $68.0 \%$ \\
\hline
\end{tabular}

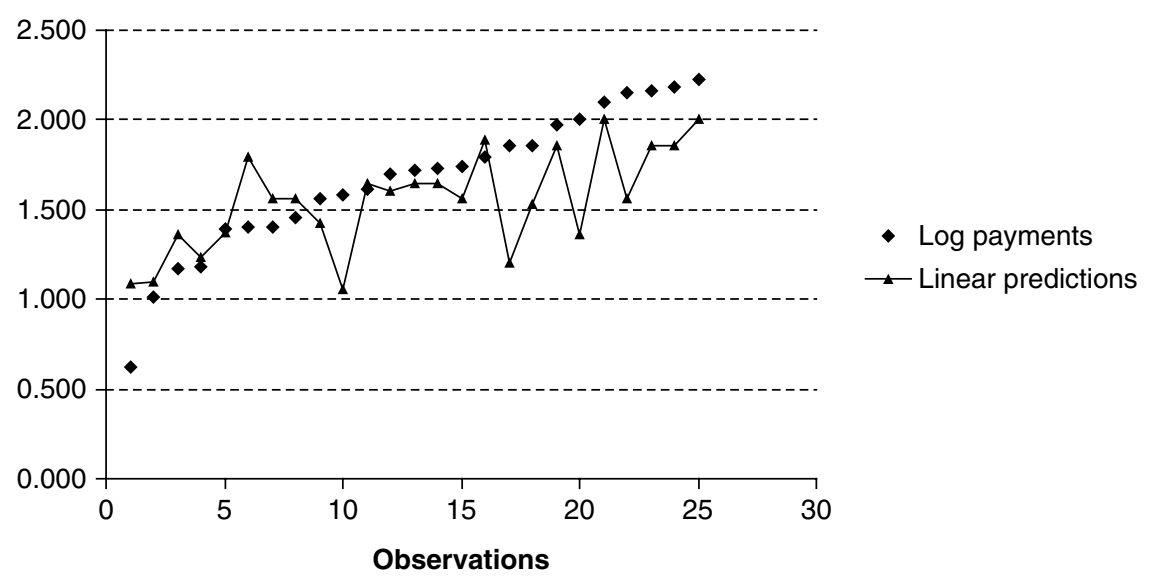

Figure 3: Predicted and observed log values in ascending order of coastal ecosystem values. 


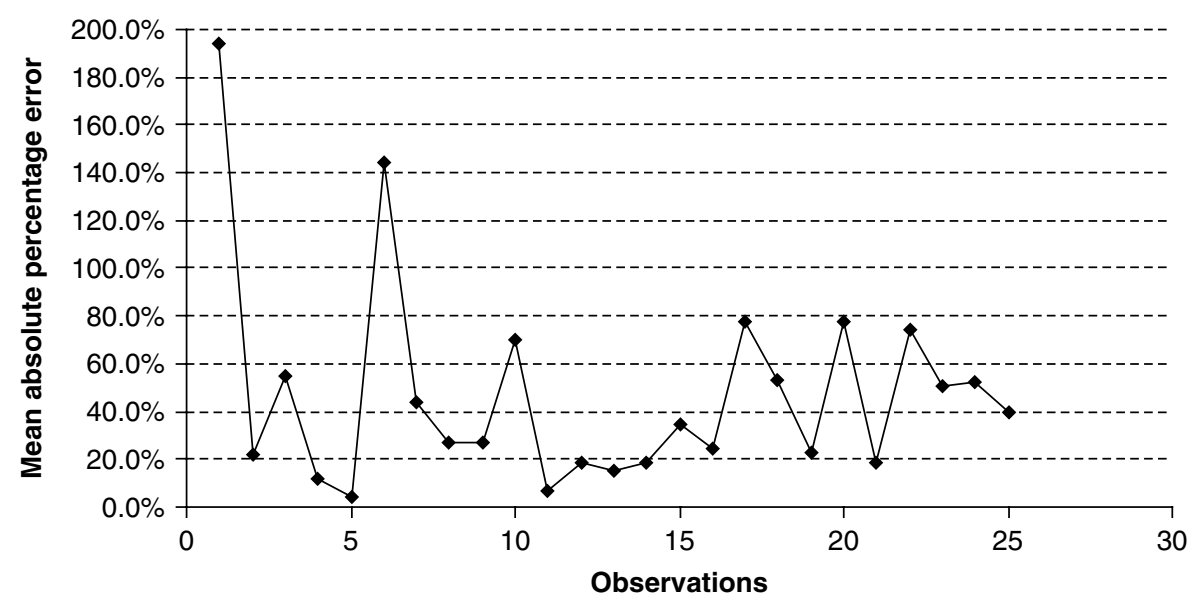

Figure 4: Mean absolute percentage error in ascending order of coastal ecosystem values.

about $60 \%$ of the out-of-sample value transfers report errors lower than $50 \%$. According to the above-mentioned validation results, it can be concluded that the meta-regression function (namely the one from model C) can be applied in several coastal ecosystems as a primary indicator of the potential benefits resulting from the protection and/or the restoration of coastal systems. However, because of lack of socio-economic variables, it would be rather difficult to consider this function as a general benefit transfer for accurate valuation of coastal ecosystems.

\section{CONCLUSIONS}

In this paper the variation in the economic values of coastal ecosystems, as derived from a selected set of CV case studies, was examined by means of a meta-analysis. The aim of this analysis was to attribute the heterogeneity in CV values to several methodological, study area and coastal functions characteristics of the primary case studies. To achieve this task, both summary statistics and econometric analyses were employed. For the summary statistics calculations, the WTP values were partitioned into 10 potential explanatory factors and the average WTP estimates were calculated for each subcategory of the explanatory factors.

With regard to the econometric analysis, an ordinary least square technique was used in order to estimate the meta-regression function. The results of this procedure showed that the most significant determinants of the variation in coastal ecosystem values are the study area characteristics. That is, the environmental threats in the areas under study seem to have an important effect on their environmental values. Bacteriological threats are positively related to higher coastal ecosystem values, while eutrophication problems are usually connected to lower WTP levels for ecosystem protection and/or restoration. Furthermore, contrary to previous meta-analysis experience, there are no positive 'returns of scale' due to the size of coastal ecosystems. Direct ecosystem values, as expected, significantly increase the total value of the aforementioned natural resources. A notable effect of the CV survey design was also detected from the meta-regression analysis. Particularly, the analytical presentation of environmental scenarios, the type of elicitation format and the level of higher bid choice are all found to be determinative factors of the heterogeneity of coastal ecosystem values.

According to the out-of-sample validation of the meta-regression model, the resulting estimators could be applied in the form of a benefit transfer to a preliminary assessment of coastal ecosystems. 
However, the significantly high value of the constant term in the meta-regression model should be noted, which is an indicator that some important factors should also be incorporated into the analysis. Therefore, in order to obtain more robust and reliable benefit transfer functions it would be useful to take into consideration some additional socio-economic variables of the reference sites (e.g. population density, income, age), which were not considered in this paper due to lack of primary data reflecting these variables.

\section{REFERENCES}

[1] Mitchell, R.C. \& Carson, R.T., Using Surveys to Value Public Goods: The Contingent Valuation Method, Resources for the Future: Washington, DC, 1989.

[2] Brouwer, R., Langford, I.H., Bateman, I.J. \& Turner, R.K., A meta-analysis of wetland contingent valuation studies. Regional Environmental Change, 1(1), pp. 47-57, 1999. doi:10.1007/s101130050007

[3] Woodward, R.T. \& Wui, Y.S., The economic value of wetland services: a meta-analysis. Ecological Economics, 37(2), pp. 257-270, 2001. doi:10.1016/S0921-8009(00)00276-7

[4] Brander, L.M., Florax, R.J. \& Vermaat, J.E., The empirics of wetland valuation: a comprehensive summary and meta-analysis of the literature. Environmental and Resource Economics, 33(2), pp. 223-225, 2006. doi:10.1007/s10640-005-3104-4

[5] Ghermandi, A., van den Bergh, J.C.J.M., Brander, L.M., de Groot, H.L.F. \& Nunes, P., Exploring diversity: a meta-analysis of wetland conservation and creation. Working paper, Free University of Amsterdam, 2007.

[6] Enjolras, G. \& Boisson, J.M., Valuing lagoons using a meta-analytical approach: methodological and practical issues. Working Papers 08-05, LAMETA, University of Montpellier, 2008.

[7] Carter, R.W.G., Coastal Environments, Academic Press: London, 1988.

[8] De Groot, R.S., Wilson, M.A. \& Boumans, R.M.J., A typology for the classification, description and valuation of ecosystem functions, goods and services. Ecological Economics, 41(3), pp. 393-408, 2002. doi:10.1016/S0921-8009(02)00089-7

[9] Costanza, R., D’Arge, R., de Groot, R., Farber, S., Grasso, M., Hannon, B., Limburg, K., Naeem, S., O’Neill, R.V., Paruelo, J., Raskin, R.G., Sutton, P. \& Van den Belt, M., The value of the world's ecosystem services and natural capital. Nature, 387, pp. 253-260, 1997. doi:10.1038/387253a0

[10] Emerton, L., Counting Coastal Ecosystems as an Economic Part of Development Infrastructure, IUCN Ecosystems and Livelihoods Group Asia, Colombo, Sri Lanka, 2006.

[11] Latinopoulos, D., Economic valuation of irrigation water: implications from a meta-analysis. Proc. of the 8th International Conference on Environmental Science and Technology, Lemnos Island, Vol. A, pp. 531-538, 2003.

[12] Bergstrom, J.C. \& Taylor, L.O., Using meta-analysis for benefits transfer: theory and practice. Ecological Economics, 60(2), pp. 351-360, 2006. doi:10.1016/j.ecolecon.2006.06.015

[13] Alberini, A., Rosato, P., Longo, A. \& Zanatta, V., Information and willingness to pay in a contingent valuation study: the value of S. Erasmo in the Lagoon of Venice. Journal of Environmental Policy and Management, 48(2), pp. 155-176, 2005.

[14] Atkins, J. \& Burdon, D., An initial economic evaluation of water quality improvements in the Randers Fjord, Denmark. Marine Pollution Bulletin, 53(1-4), pp. 195-204, 2006. doi:10.1016/j.marpolbul.2005.09.024

[15] Barton, D., The transferability of benefit transfer: contingent valuation of water quality improvements in Costa Rica. Ecological Economics, 42(1-2), pp. 147-164, 2002. doi:10.1016/S0921-8009(02)00044-7 
[16] Brouwer, R. \& Bronda, R., The cost and benefits of a revised European bathing water directive in the Netherlands. Cost Benefit Analysis and Water Resources Management, ed. R. Brouwer \& D. Pearce, Edward Elgar Publishing: Cheltenham, UK, pp. 251-269, 2005.

[17] Choe, K., Whittington, D. \& Lauria, D.T., The economic benefits of surface water quality improvements in developing countries: a case study of Davao, Philippines. Land Economics, 72(4), pp. 519-527, 1996. doi:10.2307/3146913

[18] Georgiou, S., Langford, I., Bateman, I. \& Turner, R., Determinants of willingness to pay for reductions in environmental health risks: a case study of bathing water quality. Environment and Planning A, 30, pp. 577-594, 1998. doi:10.1068/a300577

[19] Georgiou, S., Bateman, I., Langford, I. \& Day, R., Coastal bathing water health risks: developing means of assessing the adequacy of proposals to amend the 1976 EC directive. Risk Decision and Policy, 5, pp. 49-68, 2000. doi:10.1017/S1357530999100085

[20] Goffe, L., The benefit of improvement in coastal water quality: a contingent approach. Journal of Environmental Management, 45(4), pp. 305-317, 1995. doi:10.1006/jema.1995.0078

[21] Goodman, S.L., Seabrook, W. \& Jaffry, S.A., Considering conservation value in economic appraisals of coastal resources. Journal of Environmental Planning and Management, 41(3), pp. 313-336, 1998. doi:10.1080/09640569811614

[22] Hanley, N. \& Kristrom, B., What's it worth? Exploring uncertainty over values using contingent valuation. Discussion papers in economics no. 19/02, Economics Department, University of Glasgow, 2002.

[23] Jones, N., Sophoulis, C.M. \& Malesios, C., Economic valuation of coastal water quality and protest responses: a case study in Mitilini, Greece. Journal of Socio-Economics, 37(6), pp. 2478-2491, 2008. doi:10.1016/j.socec.2007.06.002

[24] Kontogianni, A., Skourtos, M., Langford, I., Bateman, I. \& Georgiou, S., Integrating stakeholder analysis in non-market valuation of environmental assets. Ecological Economics, 37(1), pp. 123-138, 2001. doi:10.1016/S0921-8009(00)00270-6

[25] Kontogianni, A., Langford, I., Papandreou, A. \& Skourtos, M., Social preferences for improving water quality: an economic analysis of benefits from wastewater treatment. Water Resources Management, 17(5), pp. 317-336, 2003. doi:10.1023/A:1025866818391

[26] Lindahl, T. \& Söderqvist, T., Who wants to save the Baltic Sea? Strategic and Environmental Uncertainty in Social Dilemmas, T. Lindahl, PhD Thesis, Department of Economics, Stockholm School of Economics, 2005.

[27] Lipton, D.W., The value of improved water quality to Chesapeake Bay Boaters. Marine Resource Economics, 19(2), pp. 1-6, 2004.

[28] Machado, F. \& Mourato, S., Improving the assessment of water related health impacts: evidence from coastal waters in Portugal. CSERGE Working Paper, GEC 99-09, University of East Anglia, Norwich, UK, 1999.

[29] Mourato, S., Georgiou, S., Ozdemiroglu, E., Newcombe, J. \& Howarth, A., Bathing Water Directive revisions: What are the benefits to England and Wales? A stated preference study. CSERGE Working Paper, ECM 03-12, University of East Anglia, Norwich, UK, 2002.

[30] Niklitschek, M. \& Leon, J., Combining intended demand and yes/no responses in the estimation of contingent valuation models. Journal of Environmental Economics and Management, 31(3), pp. 387-402, 1996. doi:10.1006/jeem.1996.0051

[31] Saengsupavanich, C., Seenprachawong, U., Gallardo, W. \& Shivakoti, G., Port-induced erosion prediction and valuation of a local recreational beach. Ecological Economics, 67(1), pp. 93-103, 2008. doi:10.1016/j.ecolecon.2007.11.018 
[32] Zylick, T., Bateman, I., Georgiou, S., Markowska, A., Dziegielewska, D., Turner, R., Graham, A. \& Langford, I., Contingent valuation of eutrophication damage in the Baltic Sea region. CSERGE Working Paper, GEC 95-03, University of East Anglia, Norwich, UK, 1995.

[33] McFadden, D., Contingent valuation and social choice. American Journal of Agricultural Economics, 76, pp. 689-708, 1994.

[34] Lindhjem, H. \& Navrud, S., How reliable are meta-analyses for international benefit transfers? Ecological Economics, 66(2-3), pp. 425-435, 2008. doi:10.1016/j.ecolecon.2007.10.005

[35] Rosenberger, R.S. \& Stanley, T.D., Measurement, generalization, and publication: sources of error in benefit transfers and their management. Ecological Economics, 60(2), pp. 372-378, 2006. doi:10.1016/j.ecolecon.2006.03.018 